\title{
Role of Irrigation Farming in the Perspective Development of Agriculture in Samtskhe Region
}

\author{
Besik Kalandadze ${ }^{1}$, Vazha Trapaidze ${ }^{2}$, Lamzira Lagidze ${ }^{3}, Z_{\text {Zrab Laoshvili }}{ }^{4}$, Ilia Kalandadze \\ ${ }^{1}$ Faculty of Exact and Natural Science, Chair of Soil Sciences, Iv. Javakhishvili Tbilisi State University, Tbilisi, Georgia \\ ${ }^{2}$ Faculty of Exact and Natural Science, Chair of Hydrology, Oceanology and Meteorology, Iv. Javakhishvili Tbilisi State University, Tbilisi, \\ Georgia \\ ${ }^{3}$ Faculty of Exact and Natural Science, Chair of Natural Use, Iv. Javakhishvili Tbilisi State University, Tbilisi, Georgia \\ ${ }^{4}$ Faculty of Exact and Natural Science, Chair of Regional Geography and Landscape Planning, Iv. Javakhishvili Tbilisi State University, Tbilisi, \\ Georgia \\ ${ }^{5}$ Faculty of Exact and Natural Science, Iv. Javakhishvili Tbilisi State University, Tbilisi, Georgia
}

\section{Email address:}

besik.kalandadze@tsu.ge (B. Kalandadze), vazha.trapaidze@tsu.ge (V. Trapaidze), lamzira.lagidze@tsu.ge (L. Lagidze), laoshvili@yahoo.com (Z. Laoshvili), ilo10@mail.ru (I. Kalandadze)

\section{To cite this article:}

Besik Kalandadze, Vazha Trapaidze, Lamzira Lagidze, Zurab Laoshvili, Ilia Kalandadze. Role of Irrigation Farming in the Perspective Development of Agriculture in Samtskhe Region. Earth Sciences. Special Issue: Special Issue: Modern Problems of Geography and Anthropology. Vol. 4, No. 5-1, 2015, pp. 13-18. doi: 10.11648/j.earth.s.2015040501.13

\begin{abstract}
The most important branch of economy in Samtskhe region is agriculture, and the region has quite a high potential of agricultural production. This is evidenced by the quite fruitful and diversified types of soil in the region. In respect of productivity, brown forest soils, brown meadow, grey-brown and forest sierozems in Samtskhe, with most of the agricultural plots located over them are particularly fruitful. The small irrigation channels here are similar to those found all over Georgia and in the mountainous regions of Caucasus. Their sizes, structure, water conducting capacity and irrigation efficiency are relevant to the conditions of a mountainous relief. The conducting capacity of the irrigation channels is little, and most of the channels have ground or exposed beds. Provided the melioration system is put to order and by considering the fruitful soils spread in the region it will be possible to boost the agricultural productivity significantly.
\end{abstract}

Keywords: Agriculture, Irrigation, Soil

\section{Introduction}

Samtskhe is an important region and a historicalgeographical province of Georgia. It consists of three municipalities (districts): Akhaltsikhe, Adigeni and Aspindza. Out of the branches of economy, the agrarian sector is a leading one in all three municipalities. $49 \%$ of the Gross Domestic Product is for agriculture, which employs most of the labor resources.

The role the irrigation farming plays in improving the agricultural productivity is universally known. The local population of Samtskhe has been irrigating the agricultural crops since the ancient times what is evidenced by the remains of old irrigation channels found during the archeological excavations. They mainly used small rivers and springs for irrigation. Development of irrigation farming is a necessary condition to maintain the soil productivity and improve the crop capacity.

\section{Main Results}

The climate in Samstskhe is characterized by moderate and humid climate with cold and dry winter. It is transient to the dry subtropical mountainous climate with warm and long summer. The average air temperature is $6.0-9.4^{0} \mathrm{C}$. The absolute maximum temperature of the warmest month of the year is $36-39^{\circ} \mathrm{C}$. The sum of active temperatures over $100^{\circ} \mathrm{C}$ varies between 2198 and $3,029^{\circ} \mathrm{C}$ and the sum of annual atmospheric precipitations does not exceed $469-640 \mathrm{~mm}$. This indicator falls much back the amount of the atmospheric precipitations falling in other regions of Georgia at the same altitude. As for the air humidity, the evaporation in the central and south-central parts of Meskheti exceeds the amount of fallen precipitations. In most parts of the territory, the mean annual precipitation-evaporation ratio is less than 1 varying between 0.5 and 0.8 . The average precipitation-evaporation 
ratio in the three months of the year (VII-IX) is less than 0.5, but in spring months and in the first half of summer when draught is particularly harmful for the agricultural crops, the precipitation-evaporation ratio is more than 0.5 [4]

Table 1. Dynamics of Producing Principal Agricultural Crops.

\begin{tabular}{|c|c|c|c|c|c|c|c|c|c|c|c|}
\hline \multirow{2}{*}{\multicolumn{3}{|c|}{ Description of crops }} & \multicolumn{3}{|c|}{ Adigeni District } & \multicolumn{3}{|c|}{ Aspindza District } & \multicolumn{3}{|c|}{ Akhaltsikhe District } \\
\hline & & & \multirow{2}{*}{$\begin{array}{l}\mathbf{2 0 0 4} \\
2,210\end{array}$} & \multirow{2}{*}{$\begin{array}{l}\mathbf{2 0 0 5} \\
2,160\end{array}$} & \multirow{2}{*}{$\begin{array}{l}\mathbf{2 0 0 6} \\
1920\end{array}$} & \multirow{2}{*}{$\begin{array}{l}\mathbf{2 0 0 4} \\
1,560\end{array}$} & \multirow{2}{*}{$\frac{\mathbf{2 0 0 5}}{1,510}$} & \multirow{2}{*}{$\begin{array}{l}\mathbf{2 0 0 6} \\
1,490\end{array}$} & \multirow{2}{*}{$\begin{array}{l}\mathbf{2 0 0 4} \\
4,240\end{array}$} & \multirow{2}{*}{$\begin{array}{l}\mathbf{2 0 0 5} \\
4,270\end{array}$} & \multirow{2}{*}{$\begin{array}{l}2006 \\
4,180\end{array}$} \\
\hline Cereals & Area & ha & & & & & & & & & \\
\hline Potato & Average harvest & pes. & 18.1 & 18,3 & 18,0 & 17,5 & 17,3 & 17.0 & 18.8 & 19.1 & 18.9 \\
\hline Vegetables & Total harvest & t. & 4,000 & 3,953 & 3456 & 2730 & 2,612 & 2,533 & 7,971 & 8,156 & 7,900 \\
\hline \multirow{8}{*}{ Fruit } & Area & ha & 1,465 & 1,480 & 1330 & 402 & 430 & 410 & 1,862 & 1,975 & 1,822 \\
\hline & Average harvest & pes. & 110 & 112,5 & 108,3 & 95 & 103 & 92 & 115.8 & 122.7 & 118.3 \\
\hline & Total harvest & $\mathrm{t}$. & 16,115 & 16,650 & 14,404 & 3,819 & 4,429 & 37,722 & 2,156 & 24,233 & 21,554 \\
\hline & Average harvest & pes. & 168 & 175 & 162 & 152 & 161 & 143 & 172 & 185 & 178 \\
\hline & Total harvest & $\mathrm{t}$. & 7,308 & 8,155 & 7,160 & 3359 & 4,057 & 3,303 & 9,494 & 10,786 & 9,434 \\
\hline & Area & ha & 870 & 870 & 870 & 885 & 885 & 885 & 1,055 & 1,055 & 1,055 \\
\hline & Average harvest & pes. & 32.8 & 24.2 & 10.1 & 28,1 & 25.3 & 8.1 & 30.2 & 23,3 & 8.3 \\
\hline & Total harvest & $\mathrm{t}$. & 2,854 & 2,105 & 879 & 2,487 & 2,239 & 717 & 3186 & 2458 & 876 \\
\hline
\end{tabular}

The total area of Samtskhe is 254,496 ha making $3.4 \%$ of the whole territory of Georgia. Arable lands occupy 49401 ha, perennial plants occupy 3,579 ha, forests and bushes - 92271 ha, hay-making lands and pastures - 74,914 ha, homestead land -4045 ha and the rest of the area is occupied by the lands unusable for agriculture (Fig. 1).

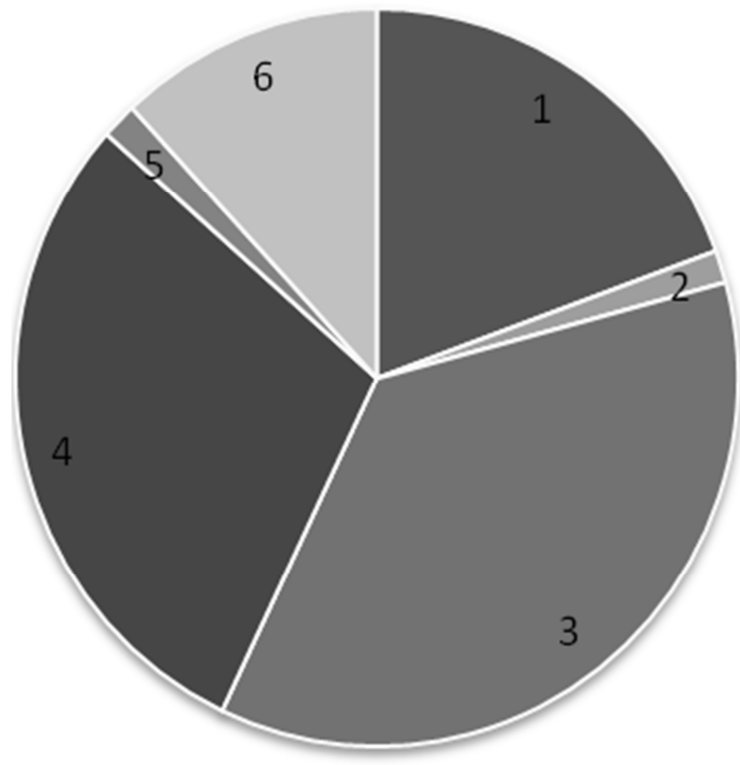

Figure 1. Landuse in Samtskhe region (1. Arable lands; 2. Perennial Plants; 3. Forests and Bushes, 4. Pastures 5. Homestead land, 6. By the lands unusable for agriculture).

Depending on the natural conditions, there are three major zones identified on the territory of Meskheti: forest and valley, mountain and forest, and alpine and subalpine zones. The first zone occupies the largest area and is most perspective for fruit-growing and vine-growing.

Another zone occupies 93,271 ha. It is quite rich in forest cover and has resort, soil-protection and water supplying functions [1.4]. The third zone occupies 58995 ha. In summer, it is covered with abundant grass and is used as pastures.

Following the natural conditions, the soils in Samtskhe are diversified. Alluvial meadow, brown alluvial and grey-brown soils typical to the transient zones of valleys associated with vertical zoning and geomorphological con ditions are common here. Brown forest and forest sierozems alternating with the mountain-meadow soils are widely spread here [2].

The principal feature of Samtskhe is that the soil zones of Samtskhe as compared to the similar zones in east Georgia are located at higher altitudes from the sea level. In the north-western part of the region, forest sierozems and mountain-meadow soils dominate, while brown forest, grey-brown, brown meadow and alluvial meadow soils dominate in the central part and brown forest and mountain-meadow forests dominate in the south-east. Mountain chernozems and Rab Humus calcareous - Rendzic leptosoils are spread as individual massifs [3].

Following the above-mentioned, one can conclude that in Samtskhe, the duration of the vegetation period, sum of active temperatures, duration of sunshine and versatile soil cover are sufficient for many agricultural crops to grow; however, at the same time, it should be noted that long draughts are common in Samtskhe, and consequently, the agricultural plots need irrigation.

The priorities of agriculture in Samtskhe are potatogrowing, vegetable-growing, cereals, fruit-growing, growing eatable products, cattle-breeding and bee-raising.

As mentioned above, Samtskhe has quite a high potential of agricultural production in respect of productivity. This is evidenced by the productive and versatile soils. In respect of productivity, brown forest soils, brown meadow and forest sierozems in Samtskhe, with $70 \%$ of the agricultural plots located over them are highly productive. These lands have quite high potential in respect of productivity provided the relevant agrotechnical rules are observed and melioration systems are developed [4].This is why in order to improve the productivity of the brown meadow soils under the plots of field, it is necessary to restore their crop capacity, particularly by using the methods of organic fertilizers (manure, crop rotation, bio-humus, compost, etc.).

In modern times, the soils are not duly alimented with organic fertilizers, little attention is paid to the systems of crop rotation and uncontrolled erosive processes take place. [5]. On 
this background, the decreasing trends of the soil productivity are the case. In thin soils developed over the highly inclined slopes, the amount of humus is little (1.5-2.5\%) because of erosive processes and consequently, the proportion of elements easy to digest for the plants is also little.

Brown meadow soils are developed in terms of plain and slightly inclined relief more. With their genesis, these

soils are very close to brown forest soils. These soils are mostly used as agricultural plots, and as a result, the humus

content in them is low and reduces with the depth. The amount of hygroscopic humidity in plots is lower and the distribution of sludge fraction is relevant to the depth. This is seen in section No. 4 (Adigeni, Lodis Dziri), brown meadow soils under the potato plants with the humus content of only $3.42 \%$ in a $0-37 \mathrm{~cm}$-thick soil layer, falling to $2.27 \%$ in a $37-49 \mathrm{~cm}$-thick layer and to $1.83 \%$ even deeper than that. This is quite a low indicator of humus content. In addition, with the humus amount, the given kinds of soils fall much back the brown forest soils. High humus conte and resultant productivity in brown forest soils is evidenced by the data of analysis of the brown soils developed under the forest in Abastumani with the humus content reaching 9,05\% and falling to $5,40 \%$ in the horizon $\mathrm{B}$ at greater depths, but nevertheless, maintains quite a high value [3].

Forest sierozems in Samtskhe are spread over the slopes of Akhaltsikhe-Imereti, Arsiani, Erusheti and Oshora-Sabaduri ridges at 1,500-2,000 masl, descending even lower at some location, e.g. on the territory of villages lower at some location, e.g. on the territory of villages Mokhi and Zarzma - in Dzindze gorge, at the height of 1,100-1,200 m asl. Humus content of sierozems, like in brown forest soils, is high, but the amount of organic undisturbed mass is litt.

Table 2. Some physical-chemical indicators of soils in Samtskhe.



For instance, a soil profile (section No. 10) was done in the environs of the Sapara Monastery at the height of $1300 \mathrm{~m}$ asl. Humus content in the turf developed at the depth of $0-10 \mathrm{~cm}$ of horizon $\mathrm{A}_{\mathrm{k}}$ was fixed at $6.52 \%$, falling to $2,80 \%$ at the depth of $10-38 \mathrm{~cm}$ of horizon A and decreasing sharply in deeper layers (Table 2; Fig 1,2).

Such a distribution of humus is mostly the result of high percentage ratio of skeletal structure of the underlying horizons. These soils have clay mechanics. Intense argillazation is observed in the middle part of the profile, the sludge fraction falls from $26,88 \%$ to $7,49 \%$ in the second horizon evidencing low filtration quality of the soil. The brown soils developed in Meskheti are generally distinguished for shorter profile and better differentiated genetic horizons.

Their accumulative horizon has a brown coloration, with a typical cloddy structure, heavy and average clay loams in the upper layers and light clay loams in the lower layers. The given type of soils in Meskheti are cultivated or used as 
agricultural plots less. It should be noted that due to high clay content and percentage of forest land, the soils are distinguished for erosion resistance. It should be noted that the necessary condition to maintain the soil productivity and improve crop capacity is the development of irrigation farming. This is also evidenced by hydrothermal coefficients in the vegetation period, which decrease drastically at maximum air temperatures (Table 3 ).

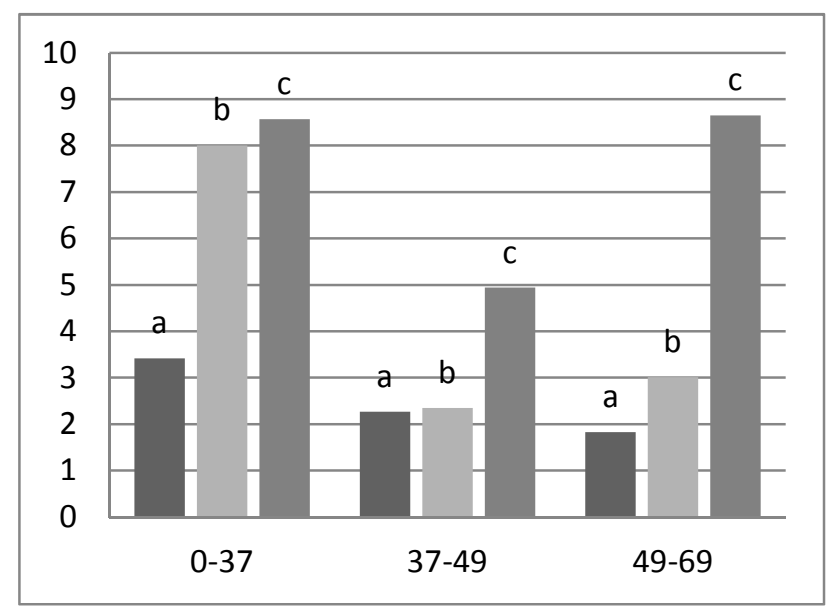

Figure 2. Adigeni, Lodis Dziri, potato.

a) Humus \% b) Hygroscopic water, \% c) Lahm



Figure 3. Khertvisi, Terraces, Brown soils.

a) Humus \% b) Hygroscopic water, \% c) Lahm

Table 3. Hydrothermal coefficients in the vegetation period.

\begin{tabular}{lllllllll}
\hline $\begin{array}{l}\text { Weather } \\
\text { station }\end{array}$ & IV & V & VI & VII & VIII & IX & X & Annual \\
\hline Adigeni & 0.74 & 1.00 & 1.08 & 0.62 & 0.45 & 0.57 & 0.77 & 0.81 \\
Aspindza & 0.65 & 0.85 & 0.89 & 0.53 & 0.40 & 0.48 & 0.59 & 0.64 \\
Akhaltsikhe & 0.79 & 0.90 & 0.98 & 0.49 & 0.43 & 0.48 & 0.83 & 0.80 \\
\hline
\end{tabular}

The small irrigation channels here are similar to those found all over Georgia and in the mountainous regions of Caucasus. Their sizes, structure, water conducting capacity and irrigation efficiency are relevant to the conditions of a mountainous relief $[6,7]$. Most of the irrigation channels in this region lack important headworks. They have great inclination and are not faced. Their banks and bottoms ruined due to frequent rains, get filled with stones and gravel and need repairs. The area of the irrigated land in Samtskhe in 1966 was 14258 ha [6] and it is 3500 ha at present. On average, $700-800 \mathrm{~m}^{3}$ water is taken per hectare as an irrigation rate [8].

There are irrigation systems in almost all villages of Adigeni municipality, with most of them being the gravity ones. The total length of the mains is $165 \mathrm{~km}$, irrigation potential is 2550 ha, while the real capacity is 1578 ha. Most of the channels are in an emergency state and need capital repairs, while some of them are in a fair state. The state of the irrigation systems in Akhaltiskhe municipality with the total length of $81,7 \mathrm{~km}$, irrigation potential of 1500 ha and real capacity of 850 ha, is better. Here, like in other municipalities, some channels need capital repairs, while others are in a fair condition. The length of the irrigation channels in Aspindza municipality is $33,5 \mathrm{~km}$ irrigating 649 ha (Tabl.4).

Table 4. Percentage of the irrigated lands.

\begin{tabular}{llll}
\hline Districts & Potential, ha & Real, ha & $\begin{array}{l}\text { Percentage of the } \\
\text { Irrigated Lands, \% }\end{array}$ \\
\hline Adigeni & 2.100 & 1.598 & 76 \\
Akhaltsikhe & 1.500 & 850 & 54 \\
Aspindza & 1.076 & 649 & 60 \\
Total & 4,676 & 3,097 & 66 \\
\hline
\end{tabular}

The agriculture in the region, like in the country, has a dual system, and it is presented by domestic farms and agro-businesses. Over $90 \%$ of the production is concentrated in small domestic farms. The size of such farming is 2.21 ha on average, usually presented by 3.8 thousand land plots with the average area of 0.59 ha. Approximately $73 \%$ of domestic farms produce agricultural products for personal use, while agriculture is a source of income for the other $25 \%$. Despite the fact that the average indicators of the productivity in the region are higher than the same indicators for the whole country, both, plant-growing and cattle-breeding are low-productive, have extensive nature, are less competitive as compared to import and use at most one-third of the potential of the branch.

The region the irrigation system operation trouble-free, with the following irrigation units worth mentioning:

- Baraleti irrigation channel (without a dam) built in 1955 with the water discharge of $0.30 \mathrm{~m}^{3}$. The channel irrigated 246 ha. The channel runs from the left side of the river Tashli-Kishli (near village Tolishi) and is $1 \mathrm{~km}$ long.

- Mechanical irrigation channel of Minadze-Chacharaki running from the river Uravli, built in 1954, with the water discharge of $0.2 \mathrm{~m}^{3}$ and irrigation area of $208 \mathrm{ha}$.

- Okhera is a primitive floodplain channel with the water discharge of $0.3 \mathrm{~m}^{3}$ and 38 ha of the irrigation area.

- Klde-Tsnisi channel runs from the river Potskhovi. Its water intake is $0.3 \mathrm{~m}^{3} / \mathrm{sec}$ and it irrigates 436 ha of land.

- Khevasheni channel, which alimented from the right bank of the river Otskhe. The headworks is near Abastumani. The channel irrigated 1.120 ha of Adigeni municipality.

- Gorgul-Kakhati semi-engineering irrigation channel 
running from the right bank of tehr iver Kvabliani. It irrigated 690 ha of Akhaltsikhe basin (150 ha of land by gravity and 540 ha mechanically).

- Ude-Arali irrigation system was laid from the right bank of the river Kvabliani. It irrigated 150 ha of land by gravity and 120 ha mechanically.

The conducting capacity of the irrigation channels here is little, and the analysis of the modern state of the irrigation systems in the region did not reveal any deficit of flow rate, i.e. the quantitative and qualitative properties of the water in the riverbeds totally meet the demand for water. The water of the rivers Uraveli, Mtkvari and Kvabliani with the amounts of water in different sections being absolutely sufficient to solve the problem of water economy in case of a $90 \%$ provision of the water demand in the vegetation period in different sections is used for irrigation purposes $[9,10]$. The main water artery, the Mtkvari cannot be actively used for irrigation to date because it flows at the lowest point of the area and without a powerful hydrotechnical premise, cannot be used for irrigation. Therefore, in order to fully activate its resource, a pumping hydroetchnical premise is to be built.

Most of the irrigation channels in Meskheti, as mentioned above, have ground or exposed beds, and need rehabilitation accomplished by Georgian United Amelioration Company, and when the rehabilitation is finished, many channels will be put to order.

The rehabilitation of Loma-Turtskhi irrigation system being the most important one in Akhaltiskhe municipality is to be considered, as well. The system heads from the river Bezhano. A 21-km-long channel is equipped with gutters and reinforced concrete slabs. The object was put to exploitation 30 years ago and served 500-600 ha of land. Due to the massive damage to the gutters along the initial section of the mains, the channel has not functioned for some recent years. Within the scope of the rehabilitation works, the damaged gutters and supports and slabs will be removed, the channel will be totally cleaned, new supports, gutters, slabs and discharge valves will be installed. In addition, the headworks, aqueducts along the mains and bridges will be totally rehabilitated. capacity is soil protection and necessary agricultural measures capable of improving the crop capacity and soil structure and protecting against erosive processes. Alimentation of soil with different organic fertilizers and introduction of the crop rotation system must be given due attention. Protection of slopes against uncontrolled erosive processes is very important. Efficient exploitation of the irrigation areas is possible by the rational distribution of the irrigation water and introduction of optimal irrigation regimes. It is true that the present-day methods to determine the irrigation regime

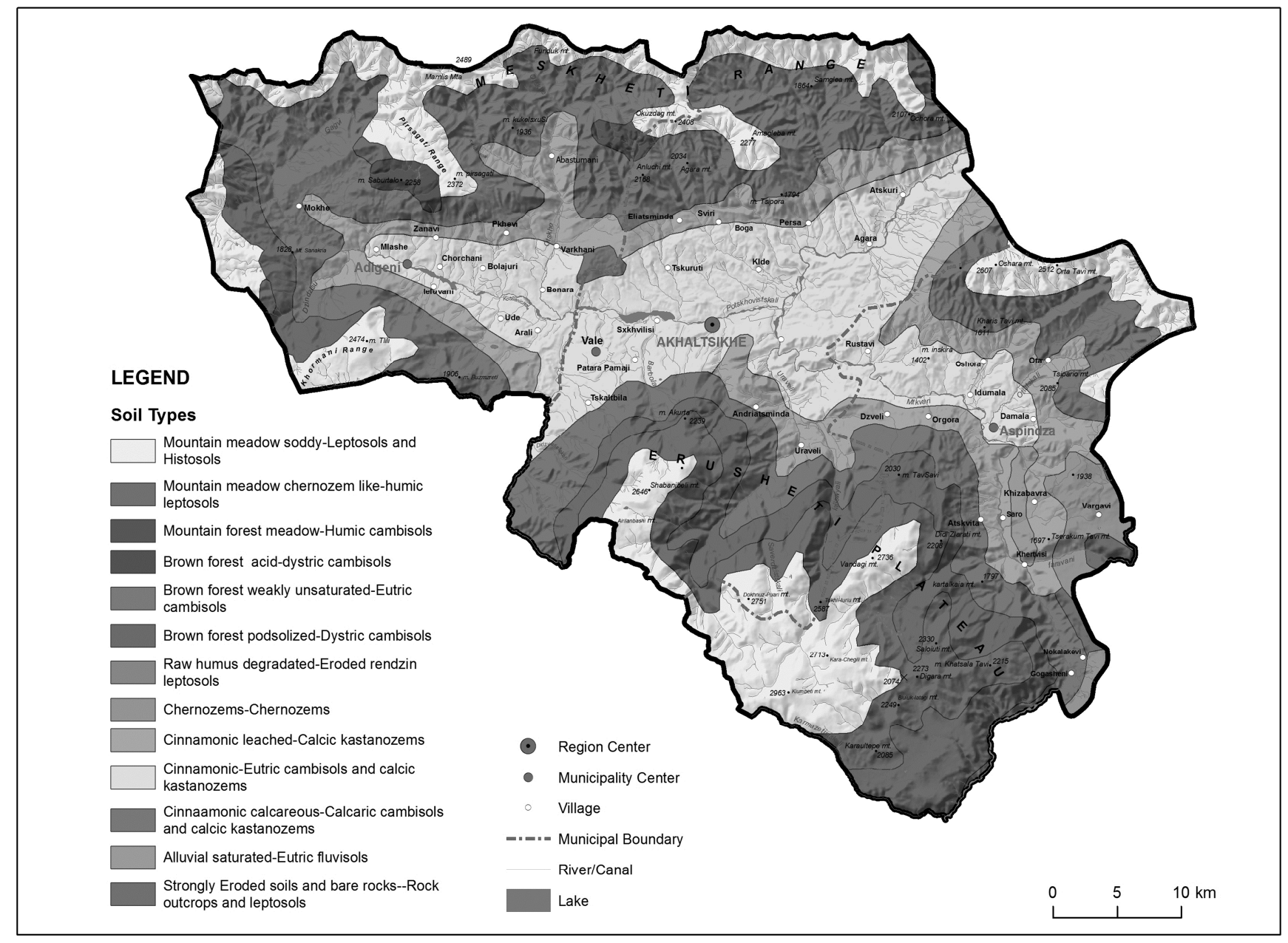

Figure 3. Soils and irrigation chanels of Samtckhe region. 


\section{Conclusions}

One of the most important factor hampering the development of agriculture in the region is the faulty operation of the irrigation system. The old system is virtually ruined expect in some rare cases. This has a certain impact on the volume and quality of production. As the results of the study of the rural infrastructure suggest, draughts have had a negative impact on the harvest in approximately $42 \%$ of the villages in the region.

A necessary condition to improve the agricultural crop capacity is soil protection and necessary agricultural measures capable of improving the crop capacity and soil structure and protecting against erosive processes. Alimentation of soil with different organic fertilizers and introduction of the crop rotation system must be given due attention. Protection of slopes against uncontrolled erosive processes is very important. Efficient exploitation of the irrigation areas is possible by the rational distribution of the irrigation water and introduction of optimal irrigation regimes. It is true that the present-day methods to determine the irrigation regime are local by nature, but they are outdated and reduce the amount of water necessary for the plants leading to the reduced crop capacity, or on the contrary, they increase it resulting in bogging and secondary salination of soil.

Provided an efficient irrigation system is put to order, in case the optimal irrigation regime is introduced and the available production potential is thoroughly used, the agricultural crop capacity can be significantly boosted, moreover when the soil and hydrological resources in the region fully support it.

\section{Acknowledgements}

The authors thank Shota Rustaveli National Scientific
Foundation as the study was accomplished within the scope of grant "Landscape-ecological evaluation of Samtskhe-Javakheti with GIS analysis for territorial planning" (Grant \#AR/105/9-280/13).

\section{References}

[1] D. Nikolaishvili, V. Trapaidze, B. Kalandadze, and et. al. "Complex evaluation of climate change - an example from Georgia's landscapes" Journal of Enviromental Biology, JEB, Vol. 36, \#1, pp.43-49, 2015.

[2] T. Urushadze, V. Bloom, Soil geography with the fundamentals of soil science, TSU, 2011, pp.118-140.

[3] T. Urushadze, Major soils of Georgia, Metsniereba, Tbilisi, 1997 pp. 96-105.

[4] R. Petriashvili, Soils of Meskheti, Soviet Georgia, 1975. pp.57-69.

[5] Kereselidze D., Machavariani L., Kalandadze B.., Trapaidze V.. Allowable Soil Erosion Rates in Georgia // ISSN: 1064-2293, Eurasian Soil Science, 2013, Vol. 46, \#3, pp. $438-446$

[6] N. Ukleba, "Use of the water resources of the Georgian SSR for people's economy", TSU, Tbilisi, 1977, pp.211-218.

[7] Kereselidze D, Bilashvili K, Trapaidze V, "Hydrological zoning of the territory of Georgia and estimation of water resources on the background of the climatic change" Proccedings 12-th International Multidisciplinary Scientific Geo-Conference \& EXPO - SGEM 2012, Vol III, pp-729-732,

[8] N. Iashvili, Melioration in agriculture, vol. 1, Tbilisi, 1970. pp.146-148.

[9] G. Khmaladze "Water resources of Georgia", Tbilisi, 2009, pp.10-11.

[10] The second national message of Georgia for Framework Convention on Climate Change. Tbilisi, 2009. pp.38-40. 